\title{
Acute Transverse and Flaccid Myelitis in Children
}

\section{Liana M. Theroux, MD \\ J. Nicholas Brenton, $M D^{*}$}

\author{
Address \\ *Department of Neurology, Division of Pediatric Neurology, University of Virginia \\ Health System, P0 Box 800394, Charlottesville, VA, 22908, USA \\ Email: jnb8h@virginia.edu
}

Published online: 3 December 2019

(C) Springer Science+Business Media, LLC, part of Springer Nature 2019

This article is part of the Topical Collection on Multiple Sclerosis and Related Disorders

Keywords Pediatric transverse myelitis - Acute flaccid myelitis $\cdot$ Inflammatory myelopathy $\cdot$ Enterovirus $\cdot$ Treatment

\begin{abstract}
Purpose of review The etiologies of myelitis in children are broad, and our understanding of inflammatory myelopathies in the pediatric population continues to evolve. Acute flaccid myelitis (AFM), increasingly linked to enterovirus infections, has risen in incidence over recent years. As with other infectious myelopathies, AFM can be challenging to distinguish from inflammatory causes of acute transverse myelitis (ATM) at initial presentation. This review outlines an approach to the treatment of children presenting with myelopathy of suspected inflammatory etiology, with attention to how management may differ in the specific case of acute flaccid myelitis.

Recent findings Although high-quality evidence is limited, intravenous corticosteroids, intravenous immunoglobulin, and plasma exchange have important roles in the acute management of ATM. Spinal cord injury in AFM, though similar to ATM in clinical presentation, is largely mediated by direct infection as opposed to a primary inflammatory process, and treatment with corticosteroids may worsen outcomes.

Summary Awareness of the distinguishing clinical features of AFM and the underlying inflammatory conditions that commonly manifest with ATM is essential to judicious selection of appropriate acute (and potentially chronic) therapies in children presenting with myelitis.
\end{abstract}

\section{Introduction}

The differential diagnosis for children presenting with signs and symptoms of acute myelopathy is broad and includes compressive, neoplastic, vascular, infectious, inflammatory, and toxic/metabolic etiologies. Magnetic resonance imaging (MRI) of the brain and spinal cord can help narrow the differential, but discerning inflammatory from infectious causes of myelitis remains a particular challenge due to the significant overlap in 
clinical and paraclinical features. Given the turn-around time needed to obtain confirmatory test results, clinicians must often make acute treatment decisions on an empiric basis. Identifying patterns from the clinical history, neurologic examination, imaging, and early laboratory results can help formulate diagnostic considerations and inform time-sensitive management. This review will focus on the distinguishing clinical characteristics and treatment paradigms of acute transverse myelitis (ATM) and acute flaccid myelitis (AFM).

Acute transverse myelitis is an immune-mediated, inflammatory attack of the spinal cord that comprises approximately $20 \%$ of all pediatric acquired demyelinating syndrome (ADS) cases $[1 \bullet]$. ATM may represent a monophasic demyelinating disorder, the initial presentation of a chronic, relapsing demyelinating syndrome, or a neurologic manifestation of a systemic autoimmune condition $[2 \bullet \bullet]$. Our understanding of both monophasic and relapsing demyelinating conditions associated with ATM has evolved substantially, particularly with the identification of antibodies mediating these diseases. Specifically, detection of antibodies against aquaporin-4 (AQP4) or myelin oligodendrocyte protein (MOG) facilitates diagnoses of neuromyelitis optica spectrum disorders (NMOSD) and MOGassociated demyelinating disorders in the appropriate clinical context. Although this evolving diagnostic stratification does have implications for optimizing longterm treatment planning, the current mainstays of acute treatment for ATM remain high-dose intravenous corticosteroids, intravenous immune globulin (IVIg), and/or plasma exchange (PLEX) [3].

One form of pediatric myelitis, which has come to the forefront in recent years, is acute flaccid myelitis (AFM). This condition, though resembling ATM in many respects, is characterized by injury to the anterior horn cells of the spinal cord [4]. The emergence of clusters of AFM in the late summer to early fall of 2014 coincided with outbreaks of respiratory infections caused by Enterovirus D68 (EV-D68), and evidence implicating this virus (among other non-polio enteroviruses, such as Enterovirus A71) as a causative agent of AFM continues to grow. Although both inflammation and infection likely contribute to neuronal injury in AFM, experimental mouse models have confirmed the presence of active infectious virus in the spinal cord [5]. This suggests a primary mechanism of direct infection of motor neurons as seen in poliomyelitis rather than a para-infectious autoimmune response as can be seen in idiopathic transverse myelitis. This distinction may have important implications for the treatment approach of AFM.

\section{Epidemiology}

The incidence of ATM in children is approximately 0.2 per 100,000 children per year $[1 \bullet, 6,7]$ and accounts for approximately $20 \%$ of all children experiencing an initial ADS [1 $\bullet$. While ATM overall exhibits a slight male predominance, a female predominance is noted among those subjects at higher risk for multiple sclerosis (MS) [1•]. The median age of presentation is between 8 and 11 years $[8 \bullet, 9,10 \bullet, 11 \bullet, 12,13]$.

An increase in cases of polio-like illness was first reported in California in $2012[14,15]$. More widely distributed outbreaks were reported in subsequent years. The establishment of case definitions by the Centers for Disease Control (CDC) enabled more accurate surveillance for cross-country acute flaccid myelitis cases. AFM has an estimated overall incidence of 1.4 cases per 100,000 [16] and affects children from infancy into young adulthood, with a median age of presentation between 5 to 9 years of age $[16,17,18 \bullet \bullet, 19,20]$.

\section{Clinical and diagnostic considerations}

Acute transverse myelitis is frequently preceded by a non-specific illness, with up to two thirds of patients ascribing to an infectious prodrome in the weeks 
preceding clinical onset [13, 21, 22]. Neurologic symptoms of ATM typically manifest with back pain followed by motor and sensory deficits. Autonomic impairment and/or bowel/bladder dysfunction may also be seen. The neurologic manifestations can evolve rapidly (over the course of hours) or more subacutely (over several days). Weakness in ATM is typically bilateral, though partial cord myelitis may result in asymmetric neurologic findings. Muscle tone and reflexes may be diminished initially; however, upper motor neuron signs (e.g., hyperreflexia, increased tone) become more apparent as the clinical course evolves. Sensory abnormalities may include numbness, paresthesias, or hyperesthesias. A spinal level may be apparent in some cases, though deficits may be patchy depending on the distribution of the cord lesions. Predictors of a relapsing demyelinating syndrome (e.g., MS, NMSOD) at the time of ATM include female sex and the presence of associated brain lesions in addition to the symptomatic spinal cord lesion(s) [8•]. ATM associated with persistent nausea, vomiting, or hiccups suggests involvement of the area postrema and is more suggestive of an NMOSD-associated myelitis [23].

Similar to ATM, the presentation of AFM almost always follows a mild respiratory or other febrile illness. AFM presents with predominately motor symptoms, though sensory changes can be seen. Distinguishing features of AFM include (1) asymmetric onset of flaccid limb weakness, commonly starting in a single arm, and (2) positive complaints of pain or paresthesia in the affected limb without an apparent sensory deficit $[18 \bullet \bullet, 24]$. Bowel and bladder dysfunction are less commonly seen in AFM compared to ATM. Flaccid tone and hyporeflexia/areflexia in the affected limb are hallmarks of AFM, but may also

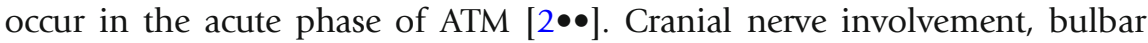
weakness, or other deficits localizing to the brainstem are seen in AFM, but altered mental status is rare and should raise suspicion for an alternative diagnosis $[18 \bullet \bullet]$.

Cerebrospinal fluid (CSF) protein and white blood cell counts may be normal in a substantial proportion of children with ATM or AFM, though increased protein and a lymphocytic pleocytosis are the most common findings $[7,13,18 \bullet \bullet, 19,22]$. The presence of unique intrathecal oligoclonal bands are typically seen in patients who will ultimately meet criteria for a diagnosis of MS [25]. Positive aquaporin- 4 antibodies are consistent with a diagnosis of NMOSD in the appropriate clinical context and should be tested in serum, as CSF testing is less sensitive [26]. Serum MOG antibodies should be checked in all pediatric myelitis patients. MOG antibodies are found in monophasic (e.g., optic neuritis, transverse myelitis, acute disseminated encephalomyelitis) and relapsing demyelinating syndromes (e.g., NMOSD, multiphasic ADEM) [27••]. Angiotensin converting enzyme levels in the CSF and serum are not sensitive or specific for the diagnosis of sarcoidosis, and imaging to identify pulmonary or other systemic manifestations is warranted [28]. Screening for underlying rheumatologic conditions that can manifest with ATM (e.g., lupus) with antinuclear antibodies, anti-double stranded antibodies, extractable nuclear antigen antibodies, and antiphospholipid antibodies should be considered.

Enteroviruses are rarely detected in the CSF of patients with AFM, and unlike poliomyelitis, EV-D68 does not shed in the stool $[24,29]$. Respiratory samples have the highest yield for EV-D68, but the virus may not be detectable beyond the first 5-7 days of infection [29]. As neurologic symptoms present days after the onset of what is otherwise a mild respiratory infection, obtaining positive 
testing in cases of AFM remains a particular challenge [29, 30].

MRI of the brain and spinal cord offers important clues to the underlying diagnosis in a child presenting with myelitis. In ATM, lesions typically involve the white matter of the spinal cord or both gray and white matter, whereas in AFM, lesions tend to be more restricted to the gray matter, particularly the anterior horn. However, this predilection for gray matter can be seen in other causes and has particularly been reported in MOG antibody-associated disorders $[31 \bullet \bullet, 32 \bullet, 33]$. Similarly, nerve root enhancement may be present in MOG antibody-associated myelitis or in AFM, with enhancement of the ventral nerve roots alone suggesting AFM $[18 \bullet \bullet, 32 \bullet, 34]$. Longitudinally extensive transverse myelitis (LETM), while classically associated with NMOSD, can be seen in MOG antibodyassociated demyelination or in AFM. Spinal cord lesions in MS tend to be focal, favor the cervical spinal cord, and are partial in cross-sectional extent, though LETM is not an uncommon finding in pediatric MS [35]. While NMOSD lesions have a predilection for the cervicothoracic spine, antiMOG-associated myelitis and AFM lesions are distributed throughout the spinal cord [32•]. T1-hypointensities on MRI may suggest a chronic relapsing demyelinating condition, such as MS or NMOSD. The presence of spinal cord cavitation is more suggestive of NMOSD [32•]. Dorsal subpial and central canal enhancement are classically associated with spinal cord sarcoidosis [36]. In AFM, brainstem lesions (particularly in the dorsal region) and cranial nerve enhancement can be seen, but supratentorial white matter lesions are not present $[18 \bullet \bullet, 34]$. The presence of supratentorial lesions on MRI is most commonly noted in pediatric MS and ADEM. ADEM is associated with diffuse, large T2-hyperintensities with indistinct borders that predominately involve the cerebral white matter, in contrast with the more circumscribed, ovoid lesions noted in MS [37]. Several radiographic examples of ATM and AFM cases from our center are presented for review in Fig. 1.

\section{Treatment}

\section{Acute management of acute transverse myelitis}

\section{Medications}

While there are no current FDA-approved therapies specifically for ATM, the acute inflammatory attack of ATM is typically managed first-line with high-dose intravenous (IV) corticosteroids [38•]. Pediatric dosing is 20 to $30 \mathrm{mg} / \mathrm{kg} / \mathrm{day}$ (up to $1 \mathrm{~g}$ /day) of IV methylprednisolone (IVMP) for 3 to 5 days. An oral prednisone taper, starting at 1 to $2 \mathrm{mg} / \mathrm{kg} /$ day and tapered over 2-4 weeks, is a consideration for patients who are improved but have achieved an incomplete recovery following high-dose IVMP administration. Placebo-controlled trials assessing the efficacy of corticosteroids in ATM do not exist; however, retrospectively acquired data suggests that early treatment with corticosteroids improves neurologic outcomes and increases the likelihood of achieving a full recovery [39].

Intravenous immunoglobulin (IVIg) is sometimes used as an adjunctive treatment to corticosteroids or as a second-line option. IVIg is dosed at $2 \mathrm{~g} / \mathrm{kg}$, 

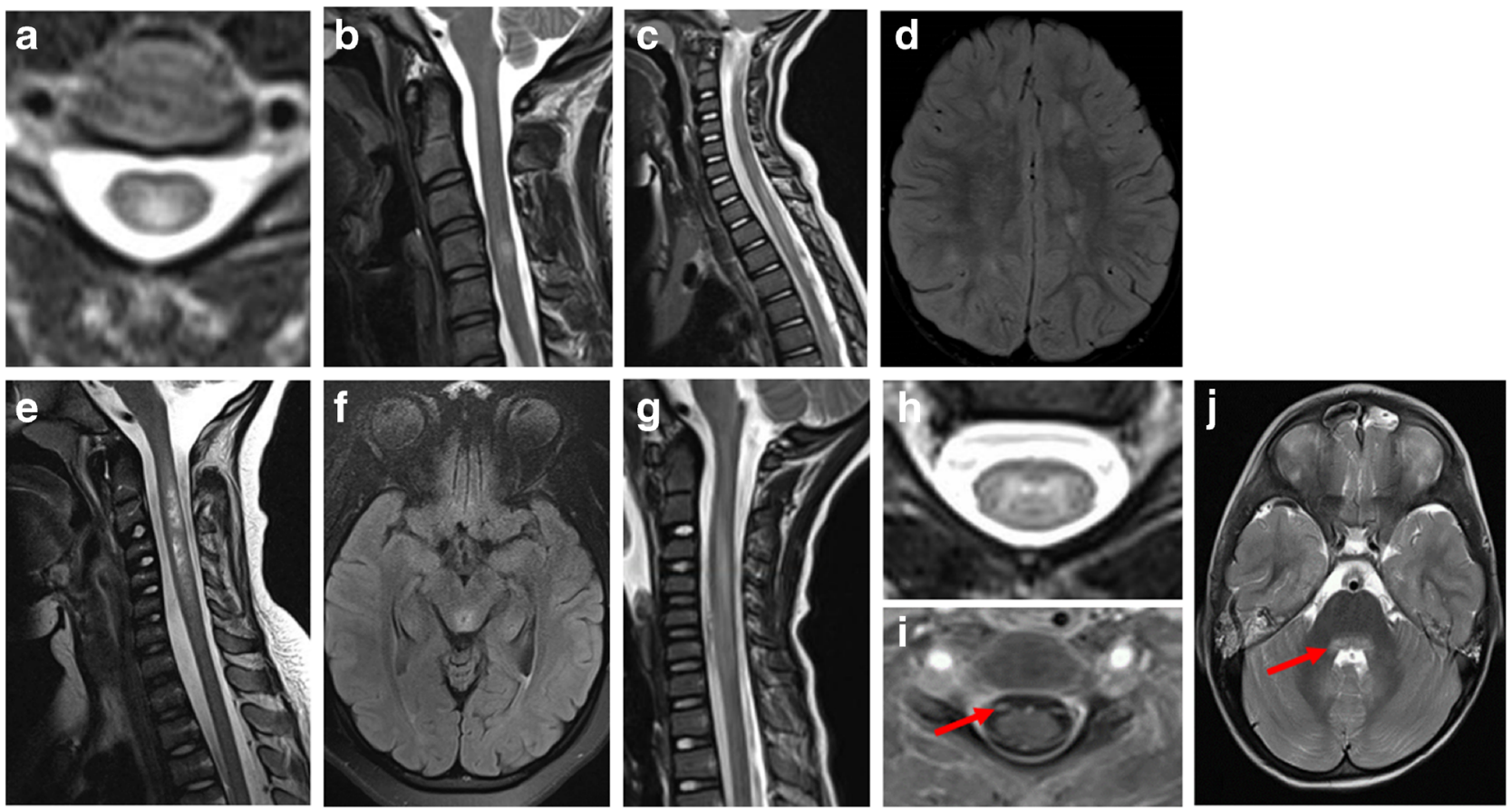

Fig. 1. a, b Idiopathic transverse myelitis in a 15-year-old girl presenting with a sensory deficit with a normal brain MRI, and a single, well-defined hyperintense lesion within the central dorsal cord at C4 as shown in both the axial T2-weighted image (a) and sagittal T2-weighted image of the cervical cord (b). c, d A 2-year-old girl with multifocal neurologic deficits, including leg weakness who was diagnosed with MOG antibody-associated ADEM. MRI of the cervical spine demonstrates a longitudinally extensive hyperintensity from C7 to T4 on T2-weighted MRI of the spine (c). Additionally, axial FLAIR imaging of the brain demonstrates multiple large, fluffy, hyperintensities throughout the white matter (d), consistent with ADEM. e, f An 8-year-old boy with weakness was found to have longitudinally extensive hyperintensities from C2 to C5 with cavitation on T2-weighted imaging of the spine (e) and was found to be AQP4 antibody positive. MRI FLAIR imaging of the brain on axial demonstrates hyperintense signal within the periaqueductal gray (f). g-j Selected MRIs from panel of patients presenting with acute flaccid myelitis. Findings include longitudinally extensive T2 hyperintensities of the central gray matter from C2 to C7 on sagittal (g) and axial (h), nerve root enhancement of the cervical spine on post-contrast T1-weighted imaging (i), and dorsal brainstem hyperintensities on axial T2weighted imaging $(\mathbf{j})$.

administered over 2 to 5 days. The data for IVIg use in acquired demyelinating syndromes is currently limited to case series and case reports [40]. To better define the role of IVIg in the treatment of ATM, the STRIVE trial was launched. This was a multicenter randomized controlled trial of IVMP alone versus IVMP plus IVIg in children and adults with ATM and/or NMOSD [41]. Unfortunately, the study was unable to achieve full recruitment, only randomizing 2 subjects [42]; however, this trial identified important barriers to studying the acute management of ATM. The importance of the research question posed in this trial remains highly relevant to the field.

Plasma exchange (PLEX) is typically used when (a) steroids are contraindicated, (b) patients are not responsive to corticosteroid treatment, or (c) the patient presents with life-threatening deficits (e.g., severe respiratory compromise). While invasive, several retrospective studies provide evidence to support the safety, tolerability, and clinical benefits of PLEX [43-46] in the setting of pediatric ATM. Typically, PLEX consists of 5 to 7 exchanges, run every other day over the course of 10 to 14 days. 
Of note, in patients with ATM and coexisting rheumatologic disease, particularly systemic lupus erythematosus, early treatment with combined IVMP and IV cyclophosphamide may prove effective [3, 47]; however, the evidence basis for this is limited. The acute treatment options for management of ATM are summarized in Table 1.

Acute management of acute flaccid myelitis

\section{Medications}

There are no high-quality clinical trials to guide acute treatment in the clinical management of AFM. The CDC task force, formed to investigate AFM and provide recommendations, ultimately concluded that there is insufficient current evidence to endorse or discourage specific treatments [50]. Patients with AFM have been primarily treated with various combinations of IVIg, intravenous steroids, and/or PLEX, though no clear correlation of specific treatments with improved outcome has been reported to date [19, 51•,52].

IVIg is the empiric treatment of choice and is dosed with the same regimen specified above [53]. IVIg has been used in the treatment of enteroviral infection in neonates and in children with agammaglobulinemia [50,54]. In the polio era, IVIg demonstrated some efficacy in the prevention of poliomyelitis when administered before poliovirus infection in children at the onset of an epidemic; however, it did not prevent progression to paralysis in patients who were already infected [19, 50, 55]. In a mouse model of EV-D68 infectious myelitis, administration of IVIg (confirmed to contain neutralizing antibodies to EVD68) prevented the occurrence of motor impairment when started on day 1 post-infection and resulted in less severe motor impairment when the treatment was initiated on days 3 to 6 post-infection, suggesting that implementation of

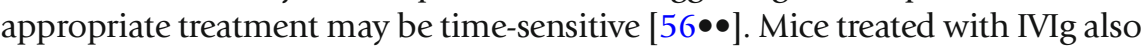
had lower mortality and lower viral titers in the spinal cord when compared to

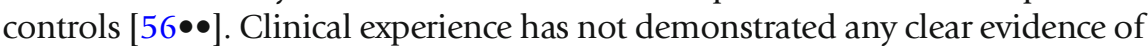
improvement with IVIg, despite the fact that testing of commercially available IVIg products confirmed the presence of neutralizing antibodies against EVD68. The difficulty in achieving treatment initiation within 3 to 6 days of infection may be a limiting factor in clinical practice. As contemporary EVD68 strains become more prevalent, levels of neutralizing antibodies in IVIg

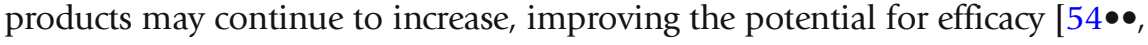
$56 \bullet \bullet]$.

High-dose IV corticosteroids have been used sequentially or in combination with IVIg, particularly when the etiology remains uncertain. Cord edema is common in AFM, and ongoing inflammation could potentially exacerbate spinal cord injury, making steroids a rational therapeutic intervention. However, steroid treatment in the setting of Enterovirus-A71, a non-polio enterovirus that can have neurologic complications (including AFM), may worsen outcomes and increase mortality [29]. In a mouse model of EV-A71 CNS infection, treatment with dexamethasone in the first few days of infection increased mortality and disease severity. In the same model, later treatment with dexamethasone showed no obvious benefit [57]. Based on these findings, the WHO concluded that steroids should be avoided in the management of EV-A71associated neuro-invasive disease [50]. Experiments in the EV-D68 mouse 


\begin{tabular}{|c|c|c|c|c|}
\hline Treatment & Indication & Dosing & $\begin{array}{l}\text { Mechanism of } \\
\text { action }\end{array}$ & Side effects \\
\hline $\begin{array}{l}\text { Intravenous } \\
\text { methylprednisolone }\end{array}$ & $\begin{array}{l}\text { - Considered first-line } \\
\text { for ATM } \\
\text { - Animal models } \\
\text { suggest that steroids } \\
\text { may worsen } \\
\text { neurologic outcomes } \\
\text { in AFM }\end{array}$ & $\begin{array}{l}20 \text { to } 30 \mathrm{mg} / \mathrm{kg} / \text { day } \\
\text { (max dose of } \\
1 \mathrm{~g} / \text { day) for } \\
3-5 \text { days }\end{array}$ & $\begin{array}{l}\text { - Modifies cytokine } \\
\text { responses } \\
\text { - Reduces T cell } \\
\text { activation } \\
\text { - Reduces blood-brain } \\
\text { barrier permeability } \\
\text { - Facilitates apoptosis of } \\
\text { activated immune } \\
\text { cells [48] }\end{array}$ & $\begin{array}{l}\text { - Hyperglycemia } \\
\text { - Hypertension } \\
\text { - Insomnia } \\
\text { - Irritability/anxiety } \\
\text { - Gastritis } \\
\text { - Weight gain }\end{array}$ \\
\hline Oral prednisone & $\begin{array}{l}\text { - May have benefit for } \\
\text { ATM immediately } \\
\text { following high-dose } \\
\text { IVMP if an improved, } \\
\text { but incomplete } \\
\text { neurologic recovery } \\
\text { is achieved } \\
\text { - Animal models } \\
\text { suggest that steroids } \\
\text { may worsen neurologic } \\
\text { outcomes in AFM }\end{array}$ & $\begin{array}{l}\text { Start at } 1 \text { to } \\
2 \mathrm{mg} / \mathrm{kg} / \text { day and } \\
\text { taper over } \\
2-4 \text { weeks }\end{array}$ & As above & As above \\
\hline $\begin{array}{l}\text { Intravenous } \\
\text { immunoglobulin }\end{array}$ & $\begin{array}{l}\text { - Used as adjunctive } \\
\text { or first-line when } \\
\text { corticosteroids are } \\
\text { contraindicated or } \\
\text { as a second-line } \\
\text { treatment for ATM } \\
\text { - First-line for AFM, } \\
\text { with animal data } \\
\text { suggesting greater } \\
\text { benefits if given early } \\
\text { in disease course }\end{array}$ & $\begin{array}{l}2 \mathrm{~g} / \mathrm{kg} \text { divided over } \\
2-5 \text { days }\end{array}$ & $\begin{array}{l}\text { - Binds circulating } \\
\text { pathologic } \\
\text { antibodies/antigens } \\
\text { - Affects cytokine } \\
\text { production and T-cell } \\
\text { proliferation [49] }\end{array}$ & $\begin{array}{l}\text { - Headache } \\
\text { - Myalgias } \\
\text { - Fever } \\
\text { - Aseptic meningitis } \\
\text { - Anaphylaxis (in IgA } \\
\quad \text { deficiency) }\end{array}$ \\
\hline Plasma exchange & $\begin{array}{l}\text { - First-line in ATM } \\
\text { when steroids are } \\
\text { contraindicated } \\
\text { or in severe, } \\
\text { life-threatening } \\
\text { cases. } \\
\text { Second-line in } \\
\text { ATM when case is } \\
\text { steroid-refractory } \\
\text { - Currently not } \\
\text { recommended in AFM } \\
\text { given the theoretical } \\
\text { risk of removing } \\
\text { native neutralizing } \\
\text { antibodies }\end{array}$ & $\begin{array}{l}5 \text { to } 7 \text { exchanges } \\
\text { provided every } \\
\text { other day over } \\
10-14 \text { days }\end{array}$ & $\begin{array}{l}\text { - Removes circulating } \\
\text { pathologic } \\
\text { antibodies and } \\
\text { immune complexes } \\
\text { from the blood }\end{array}$ & $\begin{array}{l}\text { - Procedural complications } \\
\text { - Infection } \\
\text { - Alteration of electrolyte } \\
\text { profiles } \\
\text { - Depletion of coagulation } \\
\text { factors } \\
\text { - Hypotension }\end{array}$ \\
\hline
\end{tabular}


Table 1. (Continued)

$\begin{array}{lllll}\text { Treatment } & \text { Indication } & \text { Dosing } & \text { Mechanism of } & \text { Side effects } \\ \text { action } & \text { Provided monthly } & \text { - Immune suppressant } & \text { - Nausea/vomiting/anorexia } \\ \text { Cyclophosphamide } & \text { - Considered in } & \text { (with or without } & \text { alkylating agent that } & \text { - Hemorrhagic cystitis } \\ & \text { combination with } & \text { induction) with } & \text { interferes with DNA } & \text { - Alopecia } \\ & \text { IVMP in ATM of } & \text { dose titration per } & \text { transcription of } & \text { - Amenorrhea, infertility } \\ \text { known } & \text { lymphocyte } & \text { rapidly dividing cells } & \text { - Increased risk of infections } \\ \text { rheumatologic } & \text { counts } & \text { - Affects cytokine } & \text { and secondary malignancies } \\ & \text { disease (e.g., } & & \text { expression and T cell/B } & \\ & \text { systemic lupus } & & \text { cell function } & \end{array}$

model of AFM similarly illustrated that treatment with dexamethasone worsened motor impairment, increased viral titers in the spinal cord, and resulted in

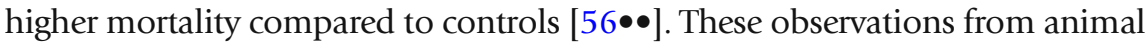
models speculate a potentially detrimental effect of steroids in AFM, particularly when used early in the course of infection.

PLEX has been used in cases of AFM without definitive evidence of benefit $[15,52]$. The appropriateness of this treatment is in question given that AFM is not an antibody-mediated disease. Furthermore, there is a distinct possibility that PLEX may be counterproductive in AFM, with the potential to remove important neutralizing antibodies formed in the setting of acute infection [50].

Fluoxetine decreases in vitro growth of EV-D68 by inhibiting the enteroviral 2C protein; however, in vivo studies of mice treated with fluoxetine did not demonstrate improvement in motor outcomes or viral titers $[56 \bullet \bullet, 58 \bullet]$. A multicenter, retrospective trial in AFM patients treated with fluoxetine (compared to untreated AFM controls) showed no improvement in neurologic outcomes [58•]. Of note, the median time to initiation of treatment in this study was 5 days after the onset of neurologic symptoms, and a subgroup analysis of those patients confirmed to have EV-D68 did demonstrate a trend toward improved outcomes with earlier initiation of fluoxetine treatment, though this did not reach statistical significance [58・].

Other antiviral agents have also been tested in vitro, with limited positive results to date. The CDC reported negative results in tests of the agents pleconaril, pocapavir, and vapendavir for antiviral activity against EV-D68 [50]. Telaprevir, an FDA-approved drug for treatment of hepatitis $\mathrm{C}$ infection, may have antiviral activity against EV-D68 by targeting the 2A protease enzyme in cell culture [59]. Picornavirus protease inhibitors (rupintrivir and V-7404) and a sialidase (DAS181) have shown in vitro antiviral activities against EVD68, but the in vivo efficacy of these agents remains to be evaluated [60].

\section{Chronic management of acute transverse myelitis}

Monophasic idiopathic ATM represents the majority of pediatric cases ( $>80 \%)$ $[8 \bullet, 9,11 \bullet, 13]$. While close clinical vigilance is needed to ensure a monophasic course, this subset of patients does not necessitate treatment with chronic immunotherapy. 
Less commonly, the first attack of ATM may represent the initial presentation of a relapsing demyelinating syndrome. Identified risk factors for relapsing disease include female sex and an abnormal brain MRI [8•]. In these particular cases, use of chronic immunotherapy should be considered. The chronic management of ATM secondary to an underlying relapsing demyelinating syndrome will vary depending on the underlying etiology and is beyond the scope of this review. In general, children with relapsing MOG antibody-associated demyelination may be treated with mycophenolate, azathioprine, rituximab, or recurrent IVIg [61•]. Children with AQP4+ NMOSD are most commonly treated with rituximab, azathioprine, and mycophenolate [23], though tocilizumab and eculizumab are viable considerations [62 6 . Pediatric MS patients should be treated with MS disease modifying therapies, which include injectables (interferons, glatiramer acetate), oral therapies (fingolimod, teriflunomide, dimethyl fumarate), and infusions (natalizumab, rituximab, ocrelizumab) [63].

\section{Chronic management of acute flaccid myelitis}

\section{Nerve transfer}

Nerve transfer is an accepted intervention for the treatment of traumatic plexopathy and peripheral nerve injury in adults. Nerve transfer has been applied to the AFM population with some success in selected cases [64]. Limitations include difficulty identifying a suitable donor nerve due to the widespread muscle dysfunction commonly seen in AFM, as well as potential viral injury to the Schwann cells, resulting in decreased ability for reinnervation. To further confound the picture, there continues to be limited observational data regarding the course of spontaneous recovery from AFM to guide surgical intervention timelines. Prolonged observation greater than 12 months may decrease the viability of the receiving nerve and muscle [64].

\section{Rehabilitation}

Early and aggressive physical therapy is a key component for the treatment of both ATM and AFM [53]. The benefit of early intensive rehabilitation was widely reported in cases of poliomyelitis. Therapy is essential for maintaining flexibility and stamina, minimizing pain and deformity, and maximizing muscle strength and functional outcomes. Ongoing clinical surveillance for potential development of a post polio-like syndrome following AFM is important [65].

\section{Prevention}

Vaccination as a means to prevent AFM is an area of high interest. Following several large scale outbreaks of EV-A71 in Asia in the late 1990s, efforts were allocated toward vaccine development. As a result, two EV-A71 vaccines were approved and are commercially available in China-with efficacy toward preventing neuro-invasive disease [24, 66]. Research to develop targets for EVD68 vaccines is currently underway; however, the feasibility of mass vaccination 


\section{Conclusion}

remains unclear, particularly as multiple different enterovirus strains have been associated with AFM [67].

Careful consideration of the clinical history, neurologic examination, neuroimaging findings, and laboratory results in a child presenting with myelitis may reveal a pattern of findings suggestive of a specific diagnosis. In transverse myelitis, whether it ultimately proves to be monophasic or the initial presentation of a relapsing demyelinating syndrome, acute treatment with high-dose IV corticosteroids is considered first-line. The addition of IVIg and/or PLEX may be appropriate in refractory or severe cases, while cyclophosphamide may have a role in acute treatment of ATM in the setting of a rheumatologic etiology.

Spinal cord injury in AFM is largely driven by an infectious myelitis, and current evidence suggests that steroid treatment has the potential to worsen neurologic outcomes. Practitioners need to be aware of the distinguishing clinical and radiographic features of AFM and the need for early testing of respiratory samples to isolate a viral pathogen. These aspects are key to achieving a correct diagnosis and to provide the most optimal, evidence-based acute management for this emerging form of myelitis. Further research efforts are needed to better identify the most safe and effective treatment(s) for acute transverse myelitis and acute flaccid myelitis.

\section{Compliance with Ethical Standards}

\section{Conflict of Interest}

Liana M. Theroux declares no potential conflicts of interest.

J. Nicholas Brenton reports personal fees for consulting for Novartis.

\section{Human and Animal Rights and Informed Consent}

This article does not contain any studies with human or animal subjects performed by any of the authors.

\section{References and Recommended Reading}

Papers of particular interest, published recently, have been

highlighted as:

- Of importance

$\bullet$ Of major importance

1. $\quad$ Banwell B, Kennedy J, Sadovnick D, Arnold DL, Magalhaes S, Wambera K, et al. Incidence of acquired demyelination of the CNS in Canadian children. Neurology. 2009;72(3):232-9.

An epidemiologic study that provides incidence of pediatric acquired demyelinating syndromes (including ATM) in a large Canadian cohort.

2.• Absoud M, Greenberg BM, Lim M, Lotze T, Thomas T, Deiva K. Pediatric transverse myelitis. Neurology. 2016;87(9 Suppl 2):S46-52.
A relatively recent review of pediatric transverse myelitis that provides more overview of its clinical features and outcomes.

3. Greenberg BM, Thomas KP, Krishnan C, Kaplin AI, Calabresi PA, Kerr DA. Idiopathic transverse myelitis: corticosteroids, plasma exchange, or cyclophosphamide. Neurology. 2007;68(19):1614-7.

4. Christy A, Messacar K. Acute flaccid myelitis associated with Enterovirus D68: a review. J Child Neurol. 2019;34(9):511-6.

5. Brown DM, Hixon AM, Oldfield LM, Zhang Y, Novotny M, Wang W, et al. Contemporary circulating 
Enterovirus D68 strains have acquired the capacity for viral entry and replication in human neuronal cells. MBio. 2018;9(5):e01954-18.

6. Holroyd KB, Aziz F, Szolics M, Alsaadi T, Levy M, Schiess N. Prevalence and characteristics of transverse myelitis and neuromyelitis optica spectrum disorders in the United Arab Emirates: a multicenter, retrospective study. Clin Exp Neuroimmunol. 2018;9(3):15561

7. Absoud M, Lim MJ, Chong WK, De Goede CG, Foster K, Gunny R, et al. Paediatric acquired demyelinating syndromes: incidence, clinical and magnetic resonance imaging features. Multiple sclerosis (Houndmills, Basingstoke, England). 2013;19(1):76-86

8. Deiva K, Absoud M, Hemingway C, Hernandez Y, Hussson B, Maurey $\mathrm{H}$, et al. Acute idiopathic transverse myelitis in children: early predictors of relapse and disability. Neurology. 2015;84(4):341-9.

This study employed one of the largest cohorts of pediatric ATM cases to determine prognostic factors of relapse and future disability.

9. Thomas T, Branson HM, Verhey LH, Shroff M, Stephens D, Magalhaes S, et al. The demographic, clinical, and magnetic resonance imaging (MRI) features of transverse myelitis in children. J Child Neurol.

2012;27(1):11-21.

10. De Goede CG, Holmes EM, Pike MG. Acquired transverse myelopathy in children in the United Kingdom-a 2 year prospective study. Eur J Paediatr Neurol. 2010;14(6):479-87.

This is a prospective population-based surveillance study from the UK that helped to define the incidence and outcomes of ATM in children.

11. Pidcock FS, Krishnan C, Crawford TO, Salorio CF, Trovato M, Kerr DA. Acute transverse myelitis in childhood: center-based analysis of 47 cases. Neurology. 2007;68(18):1474-80.

This is a retrospective cohort study of ATM that provides important data on the clinical characteristics of children with ATM and their ultimate neurologic outcomes.

12. Defresne $P$, Hollenberg $H$, Husson $B$, Tabarki B, Landrieu P, Huault G, et al. Acute transverse myelitis in children: clinical course and prognostic factors. J Child Neurol. 2003;18(6):401-6.

13. Alper G, Petropoulou KA, Fitz CR, Kim Y. Idiopathic acute transverse myelitis in children: an analysis and discussion of MRI findings. Mult Scler. 2011;17(1):7480.

14. Ayscue $P$, Van Haren $K$, Sheriff $H$, Waubant E, Waldron $\mathrm{P}$, Yagi S, et al. Acute flaccid paralysis with anterior myelitis-California, June 2012-June 2014. MMWR Morb Mortal Wkly Rep. 2014;63(40):903-6.

15. Van Haren K, Ayscue P, Waubant E, Clayton A, Sheriff $\mathrm{H}$, Yagi S, et al. Acute flaccid myelitis of unknown etiology in California, 2012-2015. Jama. 2015;314(24):2663-71.

16. Kane MS, Sonne C, Zhu S, Malhotra A, Van Haren K, Messacar $\mathrm{K}$, et al. Incidence, risk factors and outcomes among children with acute flaccid myelitis: a population-based cohort study in a California Health Network between 2011 and 2016. Pediatr Infect Dis J. 2019;38(7):667-72.

17. Andersen EW, Kornberg AJ, Freeman JL, Leventer RJ, Ryan MM. Acute flaccid myelitis in childhood: a retrospective cohort study. Eur J Neurol. 2017;24(8):1077-83.

18.• Elrick MJ, Gordon-Lipkin E, Crawford TO, Van Haren K, Messacar K, Thornton N, et al. Clinical subpopulations in a sample of North American children diagnosed with acute flaccid myelitis, 2012-2016. JAMA Pediatr. 2019;173(2):134-39.

19. Messacar K, Schreiner TL, Van Haren K, Yang M, Glaser CA, Tyler KL, et al. Acute flaccid myelitis: a clinical review of US cases 2012-2015. Ann Neurol. 2016;80(3):326-38

20. Greninger AL, Naccache SN, Messacar K, Clayton A, Yu $\mathrm{G}$, Somasekar S, et al. A novel outbreak enterovirus D68 strain associated with acute flaccid myelitis cases in the USA (2012-14): a retrospective cohort study. Lancet Infect Dis. 2015;15(6):671-82.

21. Kuo SC, Cho WH, Shih HI, Tu YF. Idiopathic acute transverse myelitis in children: a retrospective series. Neuropediatrics. 2015;46(5):307-12.

22. Suthar R, Sankhyan N, Sahu JK, Khandelwal NK, Singhi S, Singhi P. Acute transverse myelitis in childhood: a single centre experience from North India. Eur J Paediatr Neurol. 2016;20(3):352-60.

23. Chitnis T, Ness J, Krupp L, Waubant E, Hunt T, Olsen $\mathrm{CS}$, et al. Clinical features of neuromyelitis optica in children: US Network of Pediatric MS Centers report. Neurology. 2016;86(3):245-52.

24. Bitnun A, Yeh EA. Acute flaccid paralysis and enteroviral infections. Curr Infect Dis Rep. 2018;20(9):34.

25. Dale RC, Brilot F, Banwell B. Pediatric central nervous system inflammatory demyelination: acute disseminated encephalomyelitis, clinically isolated syndromes, neuromyelitis optica, and multiple sclerosis. Curr Opin Neurol. 2009;22(3):233-40.

26. Majed M, Fryer JP, McKeon A, Lennon VA, Pittock SJ. Clinical utility of testing AQP4-IgG in CSF: guidance for physicians. Neurol Neuroimmunol Neuroinflamm. 2016;3(3):e231.

27.• Hennes EM, Baumann M, Schanda K, Anlar B, BajerKornek B, Blaschek A, et al. Prognostic relevance of MOG antibodies in children with an acquired demyelinating syndrome. Neurology. 2017;89(9):900-8. A large, prospective multicenter study that illustrates the prognostic value of MOG antibodies in children with acquired demyelinating syndromes, including ATM.

28. Bridel C, Courvoisier DS, Vuilleumier N, Lalive PH. Cerebrospinal fluid angiotensin-converting enzyme for diagnosis of neurosarcoidosis. J Neuroimmunol. 2015;285:1-3.

29. Cassidy H, Poelman R, Knoester M, Van Leer-Buter CC, Niesters HGM. Enterovirus D68-the new polio? Front Microbiol. 2018;9:2677.

30. Messacar K, Tyler KL. Enterovirus D68-associated acute flaccid myelitis: rising to the clinical and research challenges. Jama. 2019; 321(9):831-23. 
31.• Dubey D, Pittock SJ, Krecke KN, Morris PP, Sechi E, Zalewski NL, et al. Clinical, radiologic, and prognostic features of myelitis associated with myelin oligodendrocyte glycoprotein autoantibody. JAMA Neurol. 2019;76(3):301-9.

32.• Tantsis EM, Prelog K, Alper G, Benson L, Gorman M, $\operatorname{Lim} \mathrm{M}$, et al. Magnetic resonance imaging in Enterovirus-71, myelin oligodendrocyte glycoprotein antibody, Aquaporin-4 antibody, and multiple sclerosisassociated myelitis in children. Dev Med Child Neurol. 2019;61(9):1108-16.

33. Wang C, Narayan R, Greenberg B. Anti-myelin oligodendrocyte glycoprotein antibody associated with gray matter predominant transverse myelitis mimicking acute flaccid myelitis: a presentation of two cases. Pediatr Neurol. 2018;86:42-5.

34. Gordon-Lipkin E, Munoz LS, Klein JL, Dean J, Izbudak I, Pardo CA. Comparative quantitative clinical, neuroimaging, and functional profiles in children with acute flaccid myelitis at acute and convalescent stages of disease. Dev Med Child Neurol. 2019;61(3):366-75.

35. Verhey LH, Branson HM, Makhija M, Shroff M, Banwell B. Magnetic resonance imaging features of the spinal cord in pediatric multiple sclerosis: a preliminary study. Neuroradiology. 2010;52(12):1153-62.

36. Zalewski NL, Flanagan EP. Autoimmune and paraneoplastic myelopathies. Semin Neurol. 2018;38(3):278-89.

37. Brenton JN, Banwell BL. Therapeutic approach to the management of pediatric demyelinating disease: multiple sclerosis and acute disseminated encephalomyelitis. Neurotherapeutics. 2016;13(1):84-95.

38. Scott TF, Frohman EM, De Seze J, Gronseth GS, Weinshenker BG. Evidence-based guideline: clinical evaluation and treatment of transverse myelitis: report of the Therapeutics and Technology Assessment Subcommittee of the American Academy of Neurology. Neurology. 2011;77(24):2128-34.

The most recent guidelines regarding the treatment of ATM, as provided by the American Academy of Neurology.

39. Defresne P, Meyer L, Tardieu M, Scalais E, Nuttin C, De Bont B, et al. Efficacy of high dose steroid therapy in children with severe acute transverse myelitis. J Neurol Neurosurg Psychiatry. 2001;71(2):272-4.

40. Nosadini M, Mohammad SS, Suppiej A, Sartori S, Dale RC. Intravenous immunoglobulin in paediatric neurology: safety, adherence to guidelines, and long-term outcome. Dev Med Child Neurol. 2016;58(11):118092.

41. Absoud M, Gadian J, Hellier J, Brex PA, Ciccarelli O, Giovannoni G, et al. Protocol for a multicentre randomiSed controlled TRial of IntraVEnous immunoglobulin versus standard therapy for the treatment of transverse myelitis in adults and children (STRIVE). BMJ Open. 2015;5(5):e008312.

42. Absoud M, Brex P, Ciccarelli O, Diribe O, Giovannoni $\mathrm{G}$, Hellier J, et al. A multicentre randomiSed controlled TRial of IntraVEnous immunoglobulin compared with standard therapy for the treatment of transverse myelitis in adults and children (STRIVE). Health

Technol Assess. 2017;21(31):1-50.

43. Manguinao M, Krysko KM, Maddike S, Rutatangwa A, Francisco C, Hart J, et al. A retrospective cohort study of plasma exchange in central nervous system demyelinating events in children. Mult Scler Relat Disord. 2019;35:50-4.

44. Bigi S, Banwell B, Yeh EA. Outcomes after early administration of plasma exchange in pediatric central nervous system inflammatory demyelination. J Child Neurol. 2015;30(7):874-80.

45. Llufriu S, Castillo J, Blanco Y, Ramio-Torrenta L, Rio J, Valles $\mathrm{M}$, et al. Plasma exchange for acute attacks of CNS demyelination: predictors of improvement at 6 months. Neurology. 2009;73(12):949-53.

46. Noland DK, Greenberg BM. Safety and efficacy of plasma exchange in pediatric transverse myelitis. Neurol Clin Pract. 2018;8(4):327-30.

47. Baca V, Lavalle C, Garcia R, Catalan T, Sauceda JM, Sanchez G, et al. Favorable response to intravenous methylprednisolone and cyclophosphamide in children with severe neuropsychiatric lupus. J Rheumatol. 1999;26(2):432-9.

48. Sloka JS, Stefanelli M. The mechanism of action of methylprednisolone in the treatment of multiple sclerosis. Multiple sclerosis (Houndmills, Basingstoke, England). 2005;11(4):425-32.

49. Rossi F, Dietrich G, Kazatchkine MD. Anti-idiotypes against autoantibodies in normal immunoglobulins: evidence for network regulation of human autoimmune responses. Immunol Rev. 1989;110:135-49.

50. Centers for Disease Control and Prevention (CDC). Acute flaccid myelitis: interim considerations for clinical management. 2018. https://www.cdc.gov/acuteflaccid-myelitis/hcp/clinical-management.html

51. Martin JA, Messacar K, Yang ML, Maloney JA, Lindwall J, Carry T, et al. Outcomes of Colorado children with acute flaccid myelitis at 1 year. Neurology. 2017;89(2):129-37.

A report on the outcomes in children with AFM in a Colorado cohort.

52. Nelson GR, Bonkowsky JL, Doll E, Green M, Hedlund GL, Moore KR, et al. Recognition and management of acute flaccid myelitis in children. Pediatr Neurol. 2016;55:17-21.

53. Hopkins SE, Elrick MJ, Messacar K. Acute flaccid myelitis-keys to diagnosis, questions about treatment, and future directions. JAMA Pediatr. 2019;173(2):117-8.

54. Zhang Y, Moore DD, Nix WA, Oberste MS, Weldon WC. Neutralization of Enterovirus D68 isolated from the 2014 US outbreak by commercial intravenous immune globulin products. J Clin Virol. 2015;69:172-5.

55. Hammon WM. Limitations in the use of gamma globulin in poliomyelitis. Am J Med Sci. 1953;226(2):125-30.

$56 . \bullet \quad$ Hixon AM, Clarke P, Tyler KL. Evaluating treatment efficacy in a mouse model of Enterovirus D68associated paralytic myelitis. J Infect Dis. 2017;216(10):1245-53. 
A comprehensive description of the efficacy of various treatment modalities in a mouse model of AFM.

57. Shen FH, Shen TJ, Chang TM, Su IJ, Chen SH. Early dexamethasone treatment exacerbates Enterovirus 71 infection in mice. Virology. 2014;464-465:218-27.

58. Messacar K, Sillau S, Hopkins SE, Otten C, WilsonMurphy M, Wong B, et al. Safety, tolerability, and efficacy of fluoxetine as an antiviral for acute flaccid myelitis. Neurology. 2019;92(18):e2118-e26.

Class IV evidence that fluoxetine is not associated with improved neurologic outcomes in children with AFM due to EV-68.

59. Musharrafieh R, Ma C, Zhang J, Hu Y, Diesing JM, Marty MT, et al. Validating Enterovirus D68-2A(pro) as an antiviral drug target and the discovery of telaprevir as a potent D68-2A(pro) inhibitor. J Virol. 2019;93(7):e02221-18.

60. Rhoden E, Zhang M, Nix WA, Oberste MS. In vitro efficacy of antiviral compounds against Enterovirus D68. Antimicrob Agents Chemother. 2015;59(12):7779-81.

61. Hacohen Y, Banwell B. Treatment approaches for MOG-Ab-associated demyelination in children. Curr Treat Options Neurol. 2019;21(1):2.

A recent review that focuses more specifically on a proposed treatment approach to children with MOG antibodyassociated demyelination.
62. Gombolay GY, Chitnis T. Pediatric neuromyelitis optica spectrum disorders. Curr Treat Options Neurol. 2018;20(6):19.

A recent review that focuses more specifically on the acute and chronic treatment of NMOSD.

63. Cappa R, Theroux L, Brenton JN. Pediatric multiple sclerosis: genes, environment, and a comprehensive therapeutic approach. Pediatr Neurol. 2017;75:17-28.

64. Saltzman EB, Rancy SK, Sneag DB, Feinberg Md JH, Lange DJ, Wolfe SW. Nerve transfers for Enterovirus D68-associated acute flaccid myelitis: a case series. Pediatr Neurol. 2018;88:25-30.

65. Morens DM, Folkers GK, Fauci AS. Acute flaccid myelitis: something old and something new. MBio. 2019;10(2):e00521-19.

66. Yi EJ, Shin YJ, Kim JH, Kim TG, Chang SY. Enterovirus 71 infection and vaccines. Clin Exp Vaccine Res. 2017;6(1):4-14.

67. Dai W, Zhang C, Zhang X, Xiong P, Liu Q, Gong S, et al. A virus-like particle vaccine confers protection against enterovirus D68 lethal challenge in mice. Vaccine. 2018;36(5):653-9.

\section{Publisher's Note}

Springer Nature remains neutral with regard to jurisdictional claims in published maps and institutional affiliations. 